\title{
Interaction Effects of pH and Inhibitors in Oil Palm Frond (OPF) Hemicelullosic Hydrolysate on Xylitol Production: A Statistical Study
}

\author{
Shareena Fairuz Abdul Manaf,, ${ }^{1,2}$ Abdullah Amru Indera Luthfi, ${ }^{1}$ \\ Jamaliah Md Jahim ${ }^{1,3 *}$ and Shuhaida Harun ${ }^{1,3}$ \\ ${ }^{1}$ Department of Chemical and Process Engineering, Faculty of Engineering and Built \\ Environment, Universiti Kebangsaan Malaysia, 43600 Bangi, Selangor, Malaysia \\ ${ }^{2}$ Faculty of Chemical Engineering, Universiti Teknologi MARA, \\ 40450 Shah Alam, Selangor, Malaysia \\ ${ }^{3}$ Research Centre for Sustainable Process Technology, Faculty of Engineering and Built \\ Environment, Universiti Kebangsaan Malaysia, 43600 UKM Bangi, Selangor, Malaysia \\ *Corresponding author: jamal@eng.ukm.my
}

Published online: 15 February 2017

To cite this article: Abdul Manaf, S. F. et al. (2017). Interaction effects of $\mathrm{pH}$ and inhibitors in oil palm frond (OPF) hemicelullosic hydrolysate on xylitol production: A statistical study. J. Phys. Sci., 28(Supp. 1), 241-255, https://doi.org/10.21315/jps2017.28.s1.16

To link to this article: https://doi.org/10.21315/jps2017.28.s1.16

\begin{abstract}
The degradation of sugars into less desirable compounds such as acetic acid and furfural are common during acid hydrolysis. The aim of this study was to evaluate the variables of $\mathrm{pH}$, concentration of acetic acid and furfural on the production of xylitol utilising Kluyveromyces marxianus ATCC 36907 by employing full factorial design. The ANOVA results showed that at the 95\% confidence level all three factors and interactions of initial pH of fermentation with acetic acid and furfural concentration were significantly affect the xylitol yield. The results of this experiment were fitted with the second order polynomial regression to relate the yield of xylitol and the independent variables. The fitted model showed a good agreement between the observed and predicted value of xylitol yield by Kluyveromyces marxianus ATCC 36907. The xylitol yield for bioconversion of detoxified dilute acid OPF hydrolysate was $0.29 \mathrm{~g} / \mathrm{g}$ of xylose with the presence of $4 \mathrm{~g} / \mathrm{L}$ of acetic acid and $0.5 \mathrm{~g} / \mathrm{L}$ furfural. The fermentation process was carried out at initial $\mathrm{pH}$ 6.5. Results of these experiments indicated that the regression model equation was a valid method to evaluate the relationship of response and independent variables and to predict the xylitol yield based on the composition of major inhibitors present in the dilute acid oil palm fronds $(O P F)$ hydrolysate.
\end{abstract}

Keywords: Full factorial design, pH, acetic acid, furfural, xylitol 


\section{INTRODUCTION}

Xylitol is a five-carbon sugar polyol, which is widely applied as a sugar substitute in the food, pharmaceutical and dental industries, as it has multiple properties, such as sweetness with low caloric content and inhibition of dental carries. ${ }^{1}$ The global xylitol market is estimated to be USD \$340 million per year and is expected to increase up to USD $\$ 540$ million per year within 3 years. $^{2}$ By 2020 , the global market for xylitol is estimated to reach 242,000 metric tons valued at just above USD $\$ 1$ billion. ${ }^{3}$ Presently, European countries and China have been focusing on the production of xylitol particularly from the abundant renewable resources of lignocellulosic biomass (LCB) such as from corncob and birch trees which consist of cellulose, hemicellulose and lignin. ${ }^{4-6}$

Xylitol is currently manufactured chemically through the reduction of D-xylose derived from hemicellulosic acid hydrolysis of biomass materials in the presence of Raney nickel catalysts. ${ }^{7,8}$ The LCB is a highly promising alternative carbon source which is potentially sustainable, renewable, and offering low cost and low environmental impacts. ${ }^{4,9,10}$ Lignocellulosic biomass consisting of three main components, cellulose (45\%-55\%), hemicellulose (25\%-35\%) and lignin (20\%$30 \%$ ) is considered as an excellent feedstock for the chemical synthesis since there is no food value attached to it. ${ }^{9,11}$ Generally, LCB can be categorised mainly into agricultural wastes, energy crops, and forestry residues. ${ }^{12}$ In order to overcome the recalcitrance and alter the structural hindrance of LCB for effective digestibility and component utilisation, a pretreatment stage is often required. ${ }^{13,14}$

The feasibility of LCB as feedstock for xylitol production has been explored worldwide depending on the availability of this biomass and the hydrolysis treatment applied. In Malaysia, the generation of oil palm plantation is estimated to be around 73.74 million tonnes of biomass annually and OPF is the most abundant biomass in the oil palm plantation. ${ }^{15-17}$ The interest to discover the potential of OPF as a renewable source of sugars for biochemical productions was due to the presence of glucose and xylose as the major monosaccharides in OPF, which are believed suitable to be adopted in various fermentation processes.

Autohydrolysis, steam explosion and hot compressed water have been reported used to rupture the lignocellulosic structure and solubilise the hemicelluloses sugars. ${ }^{5,18-20}$ In addition, dilute acid hydrolysis is a favourable and common method for the conversion of hemicelluloses to hexoses. Acidic hydrolysate of 
hemicellulose comprises a complex mixture of components which have been recognised as fermentation inhibitors, such as organic acid (acetic, formic and levulinic acid), furan derivatives (furfural and 5-hydroxymethylfurfural) and phenolic compounds. ${ }^{21,22}$ Consequently, the necessitating complicated detoxification of the lignocellulosic hydrolysate or the use of an inhibitor-tolerant microorganism is usually required for effective hydrolysate fermentation. ${ }^{23}$ In addition, the concentrations of these inhibitory by-products in the hydrolysates could be reduced by $\mathrm{pH}$ alteration in fermentation process. ${ }^{24}$

During acid hydrolysis, sugars can be degraded to furfural which is formed from pentoses as a result from severe condition of high temperature. ${ }^{13,25}$ Acetic acid is liberated upon solubilisation and hydrolysis of hemicellulose of the acetyl groups in the hemicellulose. ${ }^{26}$ Those compounds are being categorised as having pronounced toxicity towards microorganisms. ${ }^{27}$ Ping et al. investigated the correlation between acetic acid and $\mathrm{pH}$ performed at elevated $\mathrm{pH}$ levels of 5-7 for xylitol fermentation by $C$. tropicalis CCTCC M2012462 using non-detoxified corncob hemicellulose acid hydrolysate. ${ }^{23}$ The results indicated that the un-dissociated form of acetic acid would decrease as $\mathrm{pH}$ increases.

In recent review, the effects of these variables on the hydrolysis of some types of lignocelluloses such as corncob, olive tree cuttings, and sugarcane bagasse have been studied. ${ }^{23,28-30}$ However, the use of extent data can be difficult on a specific type of lignocellulose because these variables are not identical since they vary from one lignocellulosic material to another. Nevertheless, the levels of tolerance of microorganisms to toxic compounds differ according to the strain and cultivation conditions and the effects of these compounds on xylose to xylitol bioconversion have not been deeply investigated. ${ }^{31}$ Therefore, it is a worthwhile study to establish the suitable fermentation condition, i.e., $\mathrm{pH}$ corresponding to maximum concentration of each toxic compound that present in the hemicellulosic hydrolysate, for a particular microorganism.

The main objective of this study was to develop a model which could predict the xylitol yield as a function of variables selected. In this study, factorial design was used to determine the significant factors of $\mathrm{pH}$ and inhibitor compounds in fermentation process to produce xylitol by K. marxianus ATCC 36907. The developed regression model took into account all possible combination of effects over the response. 


\section{EXPERIMENTAL}

\subsection{Raw Materials}

OPF were collected from the oil palm estate located nearby Universiti Kebangsaan Malaysia, Selangor, Malaysia. The OPF was pressed mechanically using a conventional sugarcane juice presser to remove the juice. The OPF bagasse was air-dried until the moisture content dropped. The pressed bagasse was then sundried for up to 5 days until the moisture content was approximately $10 \%(\mathrm{w} / \mathrm{w})$. Dried OPF bagasse was then ground to a particle with diameter size of $2 \mathrm{~mm}$ using a cutting mill (Synthetic: Pulverisette19, Fritsch, Germany). The shredded sample was sieved through $0.5 \mathrm{~mm}$ mesh to remove the powdery particles. The sample was then dried further to constant moisture content below $10 \%(\mathrm{w} / \mathrm{w}) .{ }^{17}$

\subsection{Dilute Acid Hydrolysis}

The raw materials were oven dried at $45^{\circ} \mathrm{C}$ overnight to ensure low moisture content (less than 10\%). Initially, $10 \mathrm{~g}$ dry weight of solid OPF and $100 \mathrm{~mL}$ of $4 \%$ $(\mathrm{v} / \mathrm{v})$ nitric acid $\left(\mathrm{HNO}_{3}, 68 \%\right.$, J. T. Baker) were mixed together. Nitric acid was chosen for the hydrolysis of OPF due to its efficient to fractionate hemicellulose as claimed by previous studies. ${ }^{25,32,33}$ The hydrolysis was performed in an autoclave at $121^{\circ} \mathrm{C}$ for $30 \mathrm{~min}$. The liquid hydrolysate fraction obtained was adjusted to $\mathrm{pH}$ $6.5 \pm 0.5$ with $\mathrm{CaCO}_{3}$ powder and filtered to eradicate precipitate particles. The amount of concentration of sugars, acetic acid and furfural presented in the liquid hydrolysate were quantified.

\subsection{Production of xylitol using Kluyveromyces marxianus ATCC 36907}

The $K$. marxianus ATCC 36907 was cultivated in a liquid medium consisted of 30 $\mathrm{g} / \mathrm{L}$ xylose, $20 \mathrm{~g} / \mathrm{L}$ yeast extract, $2.0 \mathrm{~g} / \mathrm{L}\left(\mathrm{NH}_{4}\right)_{2} \mathrm{SO}_{4}$ and $0.1 \mathrm{~g} / \mathrm{L} \mathrm{CaCl} \cdot \mathrm{H}_{2} \mathrm{O}$ of pH 5.5 at $30^{\circ} \mathrm{C}$ with shaking at $200 \mathrm{rpm}$ for $24 \mathrm{~h}$ for inoculum purpose. The production of xylitol medium containing $30 \mathrm{~g} / \mathrm{L}$ xylose and $2.5 \mathrm{~g} / \mathrm{L}$ glucose and with additional supplements of $5.0 \mathrm{~g} / \mathrm{L}$ peptone, $3.0 \mathrm{~g} / \mathrm{L}$ yeast extract, $2.0 \mathrm{~g} / \mathrm{L}\left(\mathrm{NH}_{4}\right)_{2} \mathrm{SO}_{4}$ and $0.1 \mathrm{~g} / \mathrm{L} \mathrm{CaCl}_{2} \cdot \mathrm{H}_{2} \mathrm{O}$ were conducted in $250 \mathrm{ml}$ Erlenmeyer flasks with a working volume of $100 \mathrm{ml} .{ }^{34}$ Each flask was inoculated with $10 \%(\mathrm{v} / \mathrm{v})$ inoculum of total working volume. The culture was incubated at $30^{\circ} \mathrm{C}$ with an agitation speed of 200 $\mathrm{rpm}$ for $96 \mathrm{~h}$. The initial $\mathrm{pH}$ of the fermentation and the concentration of acetic acid and furfural were adjusted according to the various range in Table 1. For the validation of model purpose, the amount of synthetic acetic acid and furfural used was based on the concentration quantified from the liquid $\mathrm{HNO}_{3}$ hydrolysate (2.2) 
and the initial $\mathrm{pH}$ of fermentation was adjusted accordingly. All experiments were performed in triplicate.

Table 1: Values of coded factors used for the experimental design.

\begin{tabular}{lcccc}
\hline \multirow{2}{*}{ Factors } & \multirow{2}{*}{ Coded symbols } & \multicolumn{3}{c}{ Actual levels of code factors } \\
\cline { 3 - 5 } & & -1 & 0 & 1 \\
\hline $\mathrm{pH}$ & $\mathrm{X}_{1}$ & 5.5 & 6 & 6.5 \\
Acetic Acid & $\mathrm{X}_{2}$ & 0 & 2.5 & 5 \\
Furfural & $\mathrm{X}_{3}$ & 0 & 0.75 & 1.5 \\
\hline
\end{tabular}

\subsection{Analytical Method}

\subsubsection{Sugar and inhibitor concentrations}

Sugars (glucose, xylose and arabinose), acetic acid, xylitol and ethanol were quantified using high performance liquid chromatography, HPLC (UltiMate 3000 LC system, Dionex, Sunnyvale, CA). The eluted monosaccharides were detected by a refractive index (RI) detector (RefractoMax 520, ERC, Germany) set at $40^{\circ} \mathrm{C}$. Sugar analyses were performed using Rezex RPM-Monosaccharide column (300 $\mathrm{mm} \times 7.8 \mathrm{~mm}$; Phenomenex, USA), with a guard column $(50 \mathrm{~mm} \times 7.8 \mathrm{~mm})$. The sample injection volume was set at $20 \mu \mathrm{L}$. Furfural concentration was also measured by HPLC on an Agilent 1100 series with HPLC system (California, USA) with an Ultraviolet-Diode Array Detector (UV-DAD) set at $220 \mathrm{~nm}$, equipped with Gemini C-18 column (Phenomenex, USA). The column temperature was maintained at $40^{\circ} \mathrm{C}$. The mobile phase consists of $20 \mathrm{mM}$ sulphuric acid/ acetonitrile (1:10) at a flow rate of $0.8 \mathrm{ml} / \mathrm{min}$ with an injected sample volume of $20 \mu \mathrm{l}$. Each of the mobile phases was vacuum filtered and degassed. Standard curves were generated using different concentrations of mixed sugars, acetic acids and furfural.

\subsubsection{Experimental design and statistical analysis}

The design for 22 runs and the actual variables assigned for each run are shown in Table 2. The Minitab (Version 17, Minitab Inc. USA. 2016) was used for analysis of design and generating the contour plots. The factorial design composed of 3 factors, 1 block, 1 replicates and 22 total run. Regression analysis was used to determine the effective factors and to study the interaction effects between these factors. In analysing the results of the experiment, regression analysis with multiple regression equations was developed. These experiments were performed in 
triplicates and the average value of xylitol yield (g/g) over substrate was analysed by multiple regressions to fit the model Equation 1:

$$
Y=\beta_{0}+\sum \beta_{i} x_{i}+\sum \beta_{i j} x_{i} x_{j}+\sum \beta_{i} x_{i}^{2}
$$

where,

$Y=$ predicted value of $\mathrm{Yp} \mid \mathrm{s}(\mathrm{g} / \mathrm{g})$,

$\beta_{0}, \beta_{i}, \beta_{j}=$ regression coefficient of the model, and

$x_{i} x_{j}=$ independent variables

Table 2: Full factorial design of three independent factors with predicted and experimental values for xylitol yield (Yp|s).

\begin{tabular}{|c|c|c|c|c|c|}
\hline \multirow[b]{2}{*}{ Run Numbers } & \multirow[b]{2}{*}{$\begin{array}{l}\mathrm{X}_{1} \\
\mathrm{pH}\end{array}$} & \multirow[b]{2}{*}{$\begin{array}{c}\mathrm{X}_{2} \\
\text { Acetic acid }(\mathrm{g} / \mathrm{L})\end{array}$} & \multirow[b]{2}{*}{$\begin{array}{c}\mathrm{X}_{3} \\
\text { Furfural }(\mathrm{g} / \mathrm{L})\end{array}$} & \multicolumn{2}{|c|}{$\mathrm{Y}_{\mathrm{P} \mid \mathrm{S}}(\mathrm{g} / \mathrm{g})$} \\
\hline & & & & Observed & Predicted \\
\hline 1 & 6.00 & 2.50 & 0.75 & 0.22 & 0.22 \\
\hline 2 & 5.50 & 0.00 & 1.50 & 0.04 & 0.03 \\
\hline 3 & 6.50 & 5.00 & 1.50 & 0.17 & 0.18 \\
\hline 4 & 5.50 & 5.00 & 0.00 & 0.19 & 0.19 \\
\hline 5 & 6.00 & 2.50 & 0.75 & 0.21 & 0.22 \\
\hline 6 & 6.50 & 0.00 & 0.00 & 0.29 & 0.29 \\
\hline 7 & 6.50 & 0.00 & 1.50 & 0.15 & 0.15 \\
\hline 8 & 5.50 & 0.00 & 0.00 & 0.45 & 0.44 \\
\hline 9 & 6.00 & 2.50 & 0.75 & 0.21 & 0.22 \\
\hline 10 & 5.50 & 5.00 & 1.50 & 0.12 & 0.12 \\
\hline 11 & 6.50 & 5.00 & 0.00 & 0.38 & 0.37 \\
\hline 12 & 5.50 & 5.00 & 0.00 & 0.19 & 0.19 \\
\hline 13 & 6.50 & 5.00 & 0.00 & 0.37 & 0.37 \\
\hline 14 & 6.50 & 5.00 & 1.50 & 0.19 & 0.18 \\
\hline 15 & 6.00 & 2.50 & 0.75 & 0.21 & 0.22 \\
\hline 16 & 6.00 & 2.50 & 0.75 & 0.22 & 0.22 \\
\hline 17 & 5.50 & 0.00 & 1.50 & 0.03 & 0.03 \\
\hline 18 & 5.50 & 0.00 & 0.00 & 0.44 & 0.44 \\
\hline 19 & 5.50 & 5.00 & 1.50 & 0.12 & 0.12 \\
\hline 20 & 6.00 & 2.50 & 0.75 & 0.22 & 0.22 \\
\hline 21 & 6.50 & 0.00 & 1.50 & 0.15 & 0.15 \\
\hline 22 & 6.50 & 0.00 & 0.00 & 0.30 & 0.29 \\
\hline
\end{tabular}

$X_{1}=p H ; X_{2}=$ Concentration of acetic acid; $X_{3}=$ Concentration of furfural 


\section{RESULTS AND DISCUSSION}

\subsection{Experimental Design Analysis of Xylitol Yield}

A full factorial design with 3 levels for 3 factors was applied to study the effects of $\mathrm{pH}$ and inhibitors compounds for the xylitol production by $K$. marxianus. The range of each variable is presented in Table 1 . A total of 22 runs with combination of independent variables of $\mathrm{pH}$, concentration of acetic acid and furfural were conducted. Table 2 shows the observed and predicted result corresponding to the response assigned. The yield of xylitol varies from 0.03 to $0.45 \mathrm{~g} / \mathrm{g}$ suggesting prevailing role of $\mathrm{pH}$ and inhibitor compounds on fermentation performance. The results of this experiment were fitted with the following second order polynomial regression equation (Equation 2) with an empirical relationship between the parameters and the xylitol yield.

$$
\begin{aligned}
Y= & 1.2676-0.15 X_{1}-0.4195 X_{2}-1.245 X_{3}+0.067 X_{1} X_{2} \\
& +0.177 X_{1} X_{3}+0.331 X_{2} X_{3}-0.052 X_{1} X_{2} X_{3}
\end{aligned}
$$

where,

$Y=$ predict value of $\mathrm{Yp} \mid \mathrm{s}(\mathrm{g} / \mathrm{g})$,

$x_{1}=\mathrm{pH}$,

$x_{2}=$ concentration of acetic acid $(\mathrm{g} / \mathrm{L})$, and

$x_{3}=$ concentration of furfural $(\mathrm{g} / \mathrm{L})$

The statistical significance of the regression model was determined from the analysis of variance and $F$-test for the response model as summarised in Table 3. The $R^{2}$ value of $99.7 \%$ of the total variation suggested a higher significance and reliability of the model. The determination coefficient of adjusted $R^{2}(99.5 \%)$ was also high to indicate that the regression model has a good relationship between independent and response variables. ${ }^{35}$ The $F$-value was used to quantify the variation in the data with respect to the mean. The $F$-value and the probability value $[(\mathrm{P}>F)=0.005]$ manifested by the model was highly significant which in turn shows the model was suitable for this experiment. The high $F$-value implies that the regression models derived from the factorial design could adequately be used to predict the response. The significance of each of the coefficients in the models can be checked by P-values $(\mathrm{P}<0.005)$ may indicate the patterns of the interaction strength of each variables. ${ }^{36}$ It can be noted (Table 3 ) that the main and interactions effects are significant on xylitol yield $(\mathrm{P}<0.05)$. 
Table 3: Analysis of variance for the response function of $Y p \mid s$ by regression analysis and their significance values from ANOVA.

\begin{tabular}{cccccc}
\hline Variance source & $\begin{array}{c}\text { Degree of } \\
\text { freedom }\end{array}$ & Sum of squares & $\begin{array}{c}\text { Means of square } \\
\text { (variance) }\end{array}$ & $F$ value & $\begin{array}{c}\text { Probability }>F \\
(\alpha=0.05)\end{array}$ \\
\hline Regression & 8 & 0.264 & 0.033 & 486.98 & 0.000 \\
Linear & 3 & 0.180 & 0.060 & 886.94 & 0.000 \\
Square & 3 & 0.046 & 0.046 & 224.29 & 0.000 \\
Interaction & 1 & 0.038 & 0.038 & 562.02 & 0.000 \\
Residual error & 13 & 0.001 & 0.000 & - & - \\
Lack-of-fit & 8 & 0.000 & 0.000 & 1.55 & 0.355 \\
Pure error & 4 & 0.000 & 0.000 & - & - \\
Total & 21 & 0.264 & - & - & - \\
\hline
\end{tabular}

Coefficient of determination $R^{2}=0.9967 ;$ Adjusted $R^{2}=0.9946$

\subsection{Effect of pH, Acetic Acid and Furfural Concentration on Xylitol Production}

The xylitol yield was recorded within the range 0.03 to $0.44 \mathrm{~g} / \mathrm{g}$ of substrate consumed. The maximum xylitol yield of $0.45 \mathrm{~g} / \mathrm{g}$ could be achieved with the medium containing no acetic acid and furfural at $\mathrm{pH} 5.5$ which was close to the predicted value $(0.44 \mathrm{~g} / \mathrm{g})$ obtained from the regression model. An increase in $\mathrm{pH}$ from 5.5 to 6.5 , led to decrease up to $39 \%$ on the xylitol yield in the similar condition without the presence of inhibitors. It is known that the presence of acetic acid and furfural concentration negatively affect the bioconversion of xylose into xylitol. 29,37 Meanwhile, the $\mathrm{pH}$ had a significant influence mainly on acetic acid presence in the fermentation medium.

The regression equation (Equation 2) was used for 2D contour plots generation to evaluate the interactions variables at different conditions. Each contour in Figure 1(A), (B) and (C) represent the effect of two independent variables with respect to the response which the third variable was hold at a constant value. At pH 6.0 with various concentration of acetic acid and furfural, the average xylitol yield was approximately 0.2 . Referring to Ping et al., the optimum $\mathrm{pH}$ for xylitol production with non-detoxified hydrolysate from corncobs as substrate by $C$. tropicalis CCTCC M2012462 was 6.0 and the yield obtained was $0.61 \mathrm{~g} / \mathrm{g} .{ }^{23} \mathrm{In}$ this study, an increase $\mathrm{pH}$ condition of 6.3 to 6.5 was favourable for the xylitol yield $(0.2$ to $0.5 \mathrm{~g} / \mathrm{g})$ for high concentration of acetic acid from $2.5 \mathrm{~g} / \mathrm{L}$ to $4.8 \mathrm{~g} / \mathrm{L}$. This result suggested that the concentration of undissociated acetic acid decreased with high fermentation $\mathrm{pH} .{ }^{26}$ The high $\mathrm{pH}$ condition was preferable to lower the 
undissociated form of acetic acid and eventually inhibit the acetate formation and reduce the inhibition of acetic acid on microbial growth..$^{23,38}$ Silva et al. ${ }^{39}$ reported similar evidence explaining the effect of $\mathrm{pH}$ and acetic acid on xylitol yields. In addition, Cheng et al..$^{38}$ found that xylose consumption using C. tropicalis W103 strain was not affected by acetic acid when its concentration was lower than $2 \mathrm{~g} / \mathrm{L}$.

(A)

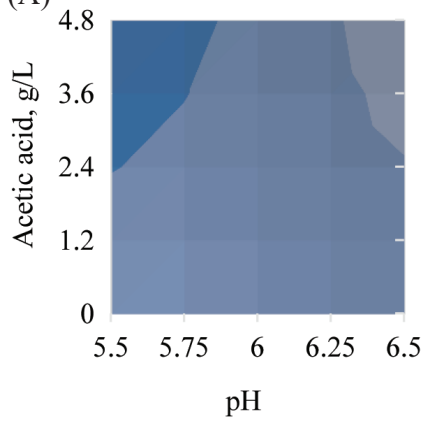

(B)

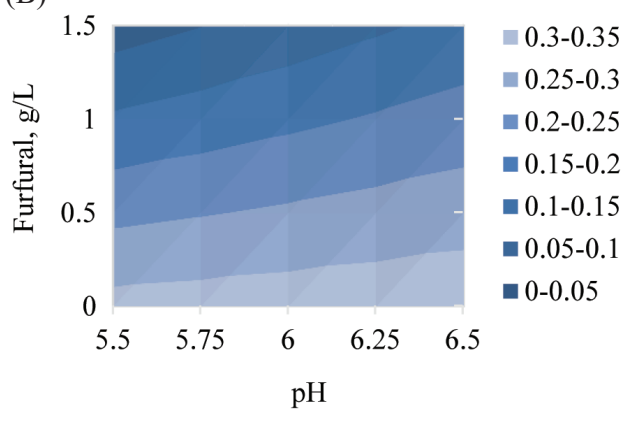

(C)

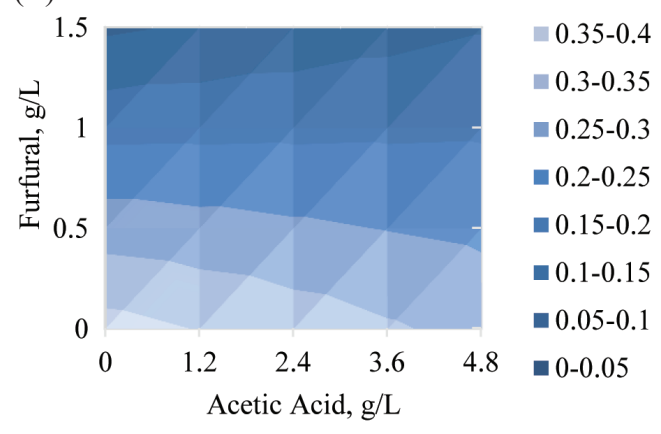

Figure 1: Contour plots on xylitol yield at variables were hold at (A) furfural $=0.75 \mathrm{~g} / \mathrm{L}$, (B) acetic acid $=2.5 \mathrm{~g} / \mathrm{L}$ and $(\mathrm{C}) \mathrm{pH}=6$.

Xylitol yield under elevated $\mathrm{pH}$ conditions decreased dramatically when the concentration of furfural further increased as depicted in Figure 2(B). Beyond the $1.5 \mathrm{~g} / \mathrm{L}$, the xylitol yield was strongly inhibited especially at very acidic condition ( $\mathrm{pH}$ less than 5.75) in mixture of glucose and xylose as carbon sources in the fermentation. The inhibitory effect of furfural decreased when the xylose was solely the main carbon source in fermentation. ${ }^{31}$ Mussatto et al. ${ }^{40}$ reported that furfural was only toxic to the microorganisms when their concentration was higher than $1 \mathrm{~g} / \mathrm{L}$. On the other hand, the interactions of furfural and acetic acid concentrations on xylitol yield are shown in contour plot of Figure 1(C). It is noted that the xylitol yield decreased linearly as the concentration of acetic acid and furfural increased. These significant interaction effects implied that the effect of 
inhibitor played a major role in xylitol production. The presence of the acetic acid and furfural in various concentrations had unfavourable effect, which indicates that increasing concentrations of these compounds had much influence on xylitol production. Acetic acid and furfural were categorised as major toxic compounds due to pronounced lethal on the microbial metabolism. ${ }^{41,42}$ These results suggest that a keen detoxification strategies are needed to reduce the inhibition caused by acetic acid and furfural when carrying out a hydrolysate fermentation of OPF after dilute acid pretreatment. ${ }^{43}$

\subsection{Validation of Model}

Further studies on the optimisation of xylitol yield were conducted based on the conditions predicted by the MINITAB software. The fermentation conditions of temperature $\left(30^{\circ} \mathrm{C}\right)$ and agitation $(200 \mathrm{rpm})$ were held constant for each run of different $\mathrm{pH}$ assigned. The concentration of acetic acid and furfural quantified from the liquid acid hydrolysate were $4 \mathrm{~g} / \mathrm{L}$ and $0.5 \mathrm{~g} / \mathrm{L}$, respectively. The predicted and observed value of $\mathrm{Yp} \mid \mathrm{s}$ at different level of $\mathrm{pH}$ was presented in Figure 2. In this work, the xylitol yield was found to be $0.43 \mathrm{~g} / \mathrm{g}$ and was close to the predicted optimum value obtained from the model $(0.45 \mathrm{~g} / \mathrm{g})$ and xylitol concentration of 10.8 at $\mathrm{pH} 5.6$ without the presence of acetic acid and furfural compounds. At $\mathrm{pH} 6.5$, the highest yield of xylitol $(0.33 \mathrm{~g} / \mathrm{g})$ with maximum concentration of xylitol at $7.3 \mathrm{~g} / \mathrm{L}$ was obtained in the presence of both acetic acid and furfural compounds. The dissociated form of acetic acid might be uphold as it could be

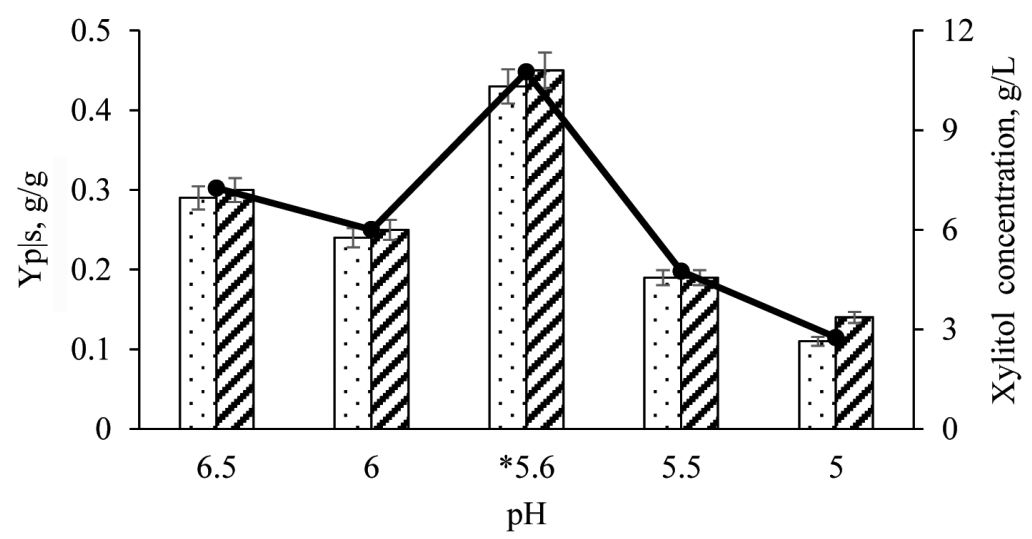

$\lessdot$ Observed $\square$ Predicted $\multimap$ Experimenal xylitol concentration

Figure 2: The observed and predicted value of xylitol yield over substrate (Yp|s) and xylitol concentration at various $\mathrm{pH}$ (“*” denotes without presence of acetic acid and furfural compounds.) 
formed when undissociated form of weak acids such as acetic acid was liposoluble and diffuses into the cytoplasm where the $\mathrm{pH}$ was almost neutral which this explained the similarity phenomena at $\mathrm{pH} 6.5$ in this study. ${ }^{26}$ However, the yield of xylitol decreased up to $44 \%$ upon $\mathrm{pH} 5$. The severe condition of fermentation in acidic level may inhibit the microbial growth at very high concentrations of acetic acid since the energy reserves of the cell for maintenance are depleted, resulting in acidification of the cytoplasm and cell death. ${ }^{44}$

\section{CONCLUSION}

Statistical study of xylitol production from dilute acid oil palm fronds (OPF) hydrolysate could overcome the limitation of fermentation process due to presence of inhibitor compounds from the acid hydrolysis process. The interactive effects of $\mathrm{pH}$, acetic acid and furfural concentration were determined to be significant. Validation experiment verified the accuracy of the model. With the amount of acetic acid and furfural from the hydrolysate in fermentation at $\mathrm{pH} 6.5$, the optimum yield of xylitol was $0.33 \mathrm{~g} / \mathrm{g}$ of xylose which was close to the predicted value $(0.29 \mathrm{~g} / \mathrm{g})$. This study provides beneficial reference for the optimisation of xylitol yield in corresponds to the effect of $\mathrm{pH}$, acetic acid and furfural compounds.

\section{ACKNOWLEDGEMENTS}

This work was financially supported by Ministry of Higher Education Malaysia through the grant provided under Long-term Research Grant Scheme (LRGS/2013/ UKM-UKM/PT/01) on project entitled Biochemical Platform for Conversion of Diversified Lignocellulosic Biomass to Priceless Precursor and Bio-based Fine Chemicals.

\section{REFERENCES}

1. Li, Z., Guo, X., Feng, X. \& Li, C. (2015). An environment friendly and efficient process for xylitol bioconversion from enzymatic corncob hydrolysate by adapted Candida tropicalis. Chem. Eng. J., 263, 249-256, https://doi.org/10.1016/j.cej.2014.11.013.

2. Prakasham, R., Rao, R. S. \& Hobbs, P. J. (2009). Current trends in biotechnological production of xylitol and future prospects. Curr. Trends Biotechnol. Pharm., 3(1), 8-36. 
3. Cramer, J. (2014). Subscription services. PR Newswire, 1-27. Retrieved on 1 January 2015 from http://www.omnistar.com/SubscriptionServices.aspx.

4. de Albuquerque, T. L. et al. (2014). Biotechnological production of xylitol from lignocellulosic wastes: A review. Process Biochem., 49(11), 17791789, https://doi.org/10.1016/j.procbio.2014.07.010.

5. Saha, B. C. (2003). Hemicellulose bioconversion. J. Ind. Microbiol. Biotechnol., 30(5), 279-291, https://doi.org/10.1007/s10295-003-0049-x.

6. Tathod, A. P. \& Dhepe, P. L. (2015). Efficient method for the conversion of agricultural waste into sugar alcohols over supported bimetallic catalysts. Bioresour. Technol., 178, 36-44, https://doi.org/10.1016/j. biortech.2014.10.036.

7. Su, B. et al. (2015). Efficient production of xylitol from hemicellulosic hydrolysate using engineered Escherichia coli. Metab. Eng., 31, 112-122, https://doi.org/10.1016/j.ymben.2015.07.003.

8. Wang, L. et al. (2011). An environmentally friendly and efficient method for xylitol bioconversion with high-temperature-steaming corncob hydrolysate by adapted Candida tropicalis. Process Biochem., 46(8), 1619-1626, https://doi.org/10.1016/j.procbio.2011.05.004.

9. Chandel, A. K., Singh, O. V. \& Rao, L. V. (2010). Biotechnological applications of hemicellulosic derived sugars: State-of-the-art. Sust. Biotech. Sources Renew. Energy, 63-81, http://dx.doi.org/10.1007/978-90-481-32959_4, https://doi.org/10.1007/978-90-481-3295-9_4.

10. Delgenes, J. et al. (1998). Biological production of industrial chemicals, ie xylitol and ethanol, from lignocelluloses by controlled mixed culture systems. Ind. Crop. Prod., 7(2), 101-111, https://doi.org/10.1016/S09266690(97)00038-1.

11. Stambuk, B. U. et al. (2008). Brazilian potential for biomass ethanol: Challenge of using hexose and pentose cofermenting yeast strains. J. Sci. Ind. Res., 67(11), 918-926.

12. Loow, Y. L. et al. (2015). Recent advances in the application of inorganic salt pretreatment for transforming lignocellulosic biomass into reducing sugars. J. Agric. Food. Chem., 63(38), 8349-8363, https://doi.org/10.1021/ acs.jafc.5b01813.

13. Loow, Y. L. et al. (2016). Typical conversion of lignocellulosic biomass into reducing sugars using dilute acid hydrolysis and alkaline pretreatment. Cellulose, 23(3), 1491-1520, https://doi.org/10.1007/s10570-016-0936-8.

14. Loow, Y.-L. et al. (2016). Role of energy irradiation in aiding pretreatment of lignocellulosic biomass for improving reducing sugar recovery. Cellulose, 23(5), 2761-2789, https://doi.org/10.1007/s10570-016-1023-x. 
15. Kelly-Yong, T. L. et al. (2007). Potential of hydrogen from oil palm biomass as a source of renewable energy worldwide. Energy Policy, 35(11), 56925701, https://doi.org/10.1016/j.enpol.2007.06.017.

16. Zahari, M. A. et al. (2012). Renewable sugars from oil palm frond juice as an alternative novel fermentation feedstock for value-added products. Biores. Technol., 110, 566-571, https://doi.org/10.1016/j.biortech.2012.01.119.

17. Luthfi, A. A. et al. (2016). Biorefinery approach towards greener succinic acid production from oil palm frond bagasse. Process Biochem., 51(10), 1527-1537, https://doi.org/10.1016/j.procbio.2016.08.011.

18. Sabiha-Hanim, S., Noor, M. A. M. \& Rosma, A. (2011). Effect of autohydrolysis and enzymatic treatment on oil palm (Elaeis guineensis Jacq.) frond fibres for xylose and xylooligosaccharides production. Biores. Technol., 102(2), 1234-1239, https://doi.org/10.1016/j.biortech.2010.08.017.

19. Sabiha-Hanim, S., Noor, M. A. M. \& Rosma, A. (2015). Fractionation of oil palm frond hemicelluloses by water or alkaline impregnation and steam explosion. Carbohydr. Polym., 115, 533-539, https://doi.org/10.1016/j. carbpol.2014.08.087.

20. Goh, C. S., Lee, K. T. \& Bhatia, S. (2010). Hot compressed water pretreatment of oil palm fronds to enhance glucose recovery for production of second generation bio-ethanol. Bioresour. Technol., 101(19), 7362-7367, https:// doi.org/10.1016/j.biortech.2010.04.048.

21. Lohmeier-Vogel, E., Sopher, C. \& Lee, H. (1998). Intracellular acidification as a mechanism for the inhibition by acid hydrolysis-derived inhibitors of xylose fermentation by yeasts. J. Ind. Microbiol. Biotechnol., 20(2), 75-81, https://doi.org/10.1038/sj.jim.2900484.

22. Palmqvist, E. \& Hahn-Hägerdal, B. (2000). Fermentation of lignocellulosic hydrolysates. II: inhibitors and mechanisms of inhibition. Biores. Technol., 74(1), 25-33, https://doi.org/10.1016/S0960-8524(99)00161-3.

23. Ping, Y., Ling, H.-Z., Song, G. \& Ge, J.-P. (2013). Xylitol production from non-detoxified corncob hemicellulose acid hydrolysate by Candida tropicalis. Biochem. Eng. J., 75, 86-91, https://doi.org/10.1016/j.bej.2013.03.022.

24. Alves, L. A. et al. (1998). Pretreatment of sugarcane bagasse hemicellulose hydrolysate for xylitol production byCandida guilliermondii. Appl. Biochem. Biotechnol., 70(1), 89-98, https://doi.org/10.1007/BF02920126.

25. Rodriguez-Chong, A. et al. (2004). Hydrolysis of sugar cane bagasse using nitric acid: a kinetic assessment. J. Food Eng., 61(2), 143-152, https://doi. org/10.1016/S0260-8774(03)00080-3.

26. Palmqvist, E. et al. (1999). Main and interaction effects of acetic acid, furfural, and p-hydroxybenzoic acid on growth and ethanol productivity of yeasts. Biotechnol. Bioeng., 63(1), 46-55, https://doi.org/10.1002/ (SICI)1097-0290(19990405)63:1\%3C46::AID-BIT5\%3E3.0.CO;2-J. 
27. Taherzadeh, M. J. et al. (1997). Characterization and fermentation of diluteacid hydrolyzates from wood. Ind. Eng. Chem. Res., 36(11), 4659-4665, https://doi.org/10.1021/ie9700831.

28. Li, Q. et al. (2012). Comparison of different alkali-based pretreatments of corn stover for improving enzymatic saccharification. Biores. Technol., 125, 193-199, https://doi.org/10.1016/j.biortech.2012.08.095.

29. Díaz, M. J. et al. (2009). Inhibition of Pichia stipitis fermentation of hydrolysates from olive tree cuttings. World J. Microbiol. Biotechnol., 25(5), 891-899, https://doi.org/10.1007/s11274-009-9966-9.

30. Rao, R. S. et al. (2006). Xylitol production from corn fiber and sugarcane bagasse hydrolysates by Candida tropicalis. Biores. Technol., 97(15), 19741978, https://doi.org/10.1016/j.biortech.2005.08.015.

31. Helle, S. et al. (2003). Effect of inhibitory compounds found in biomass hydrolysates on growth and xylose fermentation by a genetically engineered strain of S. cerevisiae. Enzyme Microb. Technol., 33(6), 786-792, https://doi.org/10.1016/S0141-0229(03)00214-X.

32. Yang, L., Lübeck, M. \& Lübeck, P. S. (2015). Effects of heterologous expression of phosphoenolpyruvate carboxykinase and phosphoenolpyruvate carboxylase on organic acid production in Aspergillus carbonarius. J. Ind. Microbiol. Biotechnol., 42(11), 1533-1545, https://doi.org/10.1007/s10295015-1688-4.

33. Zhang, R. et al. (2011). Kinetic study of dilute nitric acid treatment of corn stover at relatively high temperature. Chem. Eng. Technol., 34(3), 409-414, https://doi.org/10.1002/ceat.201000258.

34. da Silva, D. D. V. et al. (2015). Evaluation of fermentative potential of Kluyveromyces marxianus ATCC 36907 in cellulosic and hemicellulosic sugarcane bagasse hydrolysates on xylitol and ethanol production. Ann. Microbiol., 65(2), 687-694, https://doi.org/10.1007/s13213-014-0907-y.

35. Esmaeili, M. et al. (2015). A central composite design for the optimizing lipase and protease production from Bacillus subtilis PTCC 1720. Biocatal. Agric. Biotechnol., 4(3), 349-354, https://doi.org/10.1016/j.bcab.2015.05.002.

36. Ayeni, A. et al. (2013). Optimization of pretreatment conditions using full factorial design and enzymatic convertibility of shea tree sawdust. Biomass Bioenergy, 48, 130-138, https://doi.org/10.1016/j.biombioe.2012.10.021.

37. Palmqvist, E. \& Hahn-Hägerdal, B. (2000). Fermentation of lignocellulosic hydrolysates. I: inhibition and detoxification. Bioresour. Technol., 74(1), 17-24, https://doi.org/10.1016/S0960-8524(99)00160-1.

38. Cheng, K.-K. et al. (2009). Optimization of $\mathrm{pH}$ and acetic acid concentration for bioconversion of hemicellulose from corncobs to xylitol by Candida tropicalis. Biochem. Eng. J., 43(2), 203-207, https://doi.org/10.1016/j.bej. 2008.09.012. 
39. Silva, D. D. et al. (2004). Inhibitory effect of acetic acid on bioconversion of xylose in xylitol by Candida guilliermondii in sugarcane bagasse hydrolysate. Brazil. J. Microb., 35(3), 248-254, https://doi.org/10.1590/ S1517-83822004000200014.

40. Mussatto, S. I., Dragone, G. \& Roberto, I. C. (2005). Influence of the toxic compounds present in brewer's spent grain hemicellulosic hydrolysate on xylose-to-xylitol bioconversion by Candidaguilliermondii.Process Biochem., 40(12), 3801-3806, https://doi.org/10.1016/j.procbio.2005.06.024.

41. Jönsson, L. J. \& Martín, C. (2016). Pretreatment of lignocellulose: Formation of inhibitory by-products and strategies for minimizing their effects. Biores. Technol., 199, 103-112, https://doi.org/10.1016/j.biortech.2015.10.009.

42. Pereira, R. S., Mussatto, S. I. \& Roberto, I. C. (2011). Inhibitory action of toxic compounds present in lignocellulosic hydrolysates on xylose to xylitol bioconversion by Candida guilliermondii. J. Ind. Microbiol. Biotechnol., 38(1), 71-78, https://doi.org/10.1007/s10295-010-0830-6.

43. Hsu, T.-C. et al. (2010). Effect of dilute acid pretreatment of rice straw on structural properties and enzymatic hydrolysis. Biores. Technol., 101(13), 4907-4913, https://doi.org/10.1016/j.biortech.2009.10.009.

44. Larsson, S. et al. (1999). The generation of fermentation inhibitors during dilute acid hydrolysis of softwood. Enzyme Microb. Technol., 24(3), 151159, https://doi.org/10.1016/S0141-0229(98)00101-X. 
